\title{
Characteristics and formation mechanism of continuous hazes in China: a case study during the autumn of 2014 in the North China Plain
}

\author{
Y. R. Yang ${ }^{1}$, X. G. Liu ${ }^{1}$, Y. Qu ${ }^{2}$, J. L. An ${ }^{2}$, R. Jiang ${ }^{3}$, Y. H. Zhang ${ }^{4}$, Y. L. Sun ${ }^{2}$, Z. J. Wu ${ }^{4}$, F. Zhang ${ }^{5}$, W. Q. Xu' ${ }^{2}$, and \\ Q. X. $\mathrm{Ma}^{6}$ \\ ${ }^{1}$ State Key Laboratory of Water Environment Simulation, School of Environment, Beijing Normal University, Beijing \\ 100875, China \\ ${ }^{2}$ State Key Laboratory of Atmospheric Boundary Layer Physics and Atmospheric Chemistry, Institute of Atmospheric \\ Physics, Chinese Academy of Sciences, Beijing 100029, China \\ ${ }^{3}$ Shanghai Key Laboratory for Urban Ecological Processes and Eco-Restoration, School of Ecological and Environmental \\ Sciences, East China Normal University, Shanghai 200241, China \\ ${ }^{4}$ State Key Joint Laboratory of Environment Simulation and Pollution Control, College of Environmental Sciences and \\ Engineering, Peking University, Beijing 100871, China \\ ${ }^{5}$ College of Global Change and Earth System Science, Beijing Normal University, Beijing 100875, China \\ ${ }^{6}$ Research Center for Eco-Environmental Sciences, Chinese Academy of Sciences, Beijing, 100085, China
}

Correspondence to: X. G. Liu (liuxingang@bnu.edu.cn) and Y. H. Zhang (yhzhang@pku.edu.cn)

Received: 26 February 2015 - Published in Atmos. Chem. Phys. Discuss.: 15 April 2015

Revised: 26 June 2015 - Accepted: 7 July 2015 - Published: 23 July 2015

\begin{abstract}
Four extreme haze episodes occurred in October 2014 in the North China Plain (NCP). To clarify the formation mechanism of hazes in autumn, strengthened observations were conducted in Beijing from 5 October to 2 November. The meteorological parameters, satellite data, chemical compositions and optical properties of aerosols were obtained. The hazes originated from the NCP, developing in the southwest and northeast directions, with the highest concentration of $\mathrm{PM}_{2.5}$ of $469 \mu \mathrm{g} \mathrm{m}^{-3}$ in Beijing. The NCP was dominated by a weak high pressure system during the haze episode, which resulted in low surface wind speed and relatively stagnant weather. Moreover, the wind slowed down around Beijing city. The secondary aerosols $\mathrm{NO}_{3}^{-}$was always higher than that of $\mathrm{SO}_{4}^{2-}$, which indicated the motor vehicles played a more important part in the hazes in October 2014, even though the oxidation rate from $\mathrm{SO}_{2}$ to $\mathrm{SO}_{4}^{2-}$ was faster than that of $\mathrm{NO}_{x}$ to $\mathrm{NO}_{3}^{-}$. Sudden increases of the concentrations of organic matter, $\mathrm{Cl}^{-}$and $\mathrm{BC}$ (black carbon) before each haze episode implied that regional transport of pollutants by biomass burning was important for haze formation during autumn. A satellite map of fire points and
\end{abstract}

the backward trajectories of the air masses also indicated this pollution source. The distinct decrease in the PBL (planetary boundary layer) height during four haze episodes restrained the vertical dispersion of the air pollutants. Water vapor also played a vital role in the formation of hazes by accelerating the chemical transformation of secondary pollutants, leading to hygroscopic growth of aerosols and altering the thermal balance of the atmosphere.

\section{Introduction}

Haze is an atmospheric phenomenon composed of smog, dust, and vapor suspended in air, with a horizontal visibility lower than $10 \mathrm{~km}$ and an RH lower than $90 \%$ (Watson, 2002; Wu et al., 2007; Liu et al., 2013a). Haze events are attracting increasing attention because of their close relationship with human diseases (Miller et al., 2007; Araujo et al., 2008) and the alteration of the radiation budget in the atmosphere, leading to climate changes on Earth (Cahill, 1996; Jacobson, 2001). 


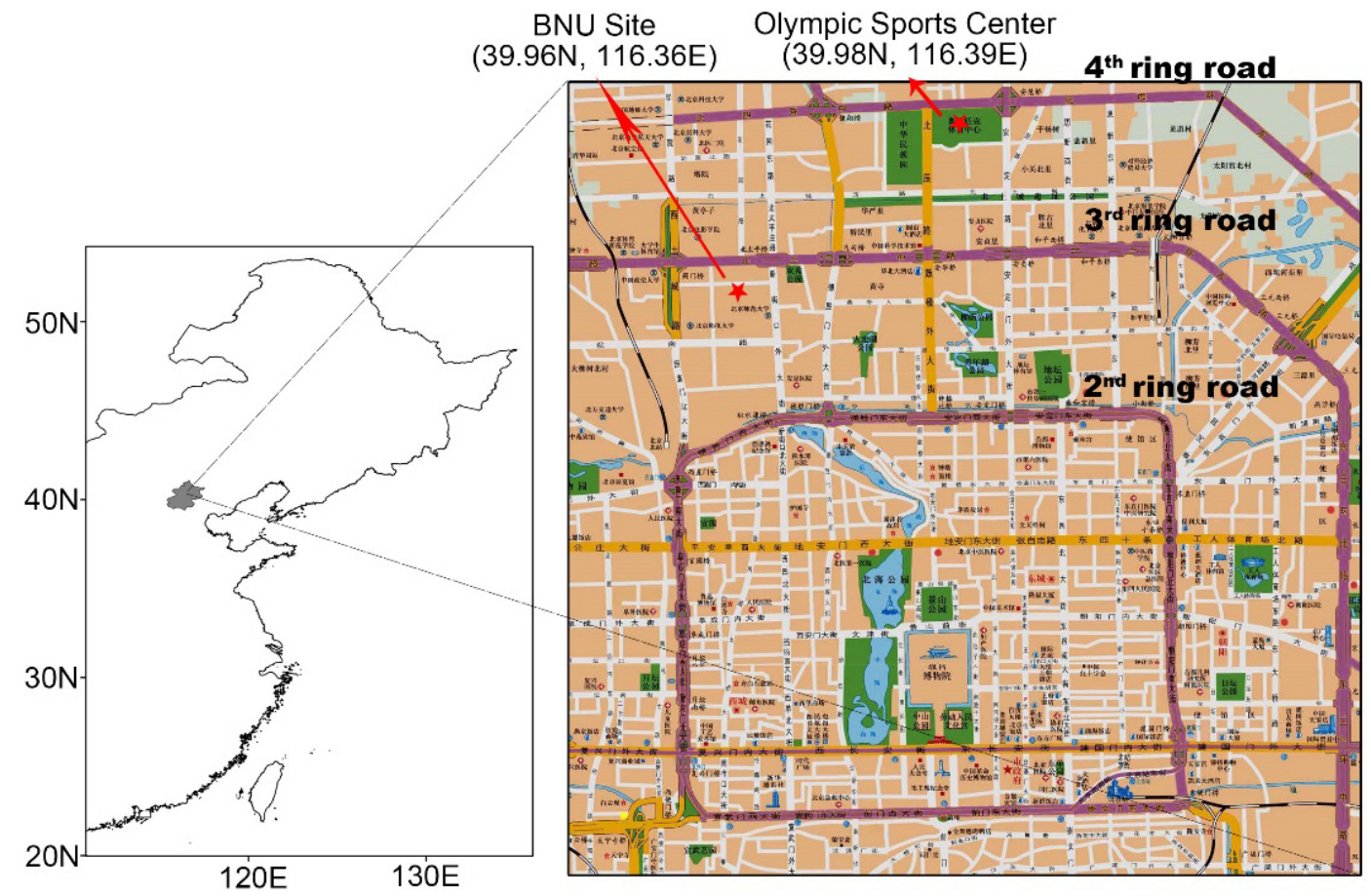

Figure 1. Observation sites in Beijing. All the data was obtained at BNU site except for gaseous pollutants, which were measured at the Olympic Sports Center by the National Environmental Bureau.

In recent years, hazes occurred frequently in China, especially in the North China Plain (NCP), which is one of the most populated and economically developed regions in China. Particulate matter was the primary pollutant during haze episodes; it occupied $85-90 \%$ of the primary pollutants in most Chinese cities throughout the year (Wang et al., 2014). Three widespread and persistent haze episodes were recorded in China in January 2013 (Yang et al., 2015; Huang et al., 2014), October 2013 and February 2014. Two of these episodes seriously influenced the NCP (one in January 2013, and the other in February 2014), which were characterized by long durations, large regions of influence and high concentrations of $\mathrm{PM}_{2.5}$ (particulate matter with an aerodynamic diameter equal or less than $2.5 \mu \mathrm{m}$ ) (Yang et al., 2015). The rapid increase of $\mathrm{PM}_{2.5}$, which was seldom reported before, confused many researchers. Most studies explained that this phenomenon was due to the intense secondary formation (e.g., heterogeneous transform of $\mathrm{SO}_{2}$ and $\mathrm{NO}_{x}$ to $\mathrm{SO}_{4}^{2-}$ and $\mathrm{NO}_{3}^{-}$) (Liu et al., 2013b; Ji et al., 2014) and the huge regional transport of pollutants (Wang et al., 2014). In addition, stationary meteorological conditions and large local emission (e.g., coal combustion in winter) were also considered to be major factors leading to such severe hazes (Liu et al., 2013b; Sun et al., 2014).

Due to the heating supply in northern China during the winter (Ma et al., 2011) and the violent photoreaction during the summer (Liao et al., 2014), most studies concerning haze events in the NCP were performed in the winter and summer. Comparatively, haze formation in autumn has been investigated less often. Liu et al. (2013b) reported a case study on haze in September 2011 in Beijing and clarified that the key factors resulting in the formation and evolution of haze episodes were stable anti-cyclone synoptic conditions at the surface, the decreasing height of the PBL (planetary boundary layer), heavy pollution emissions from urban areas, the number and size evolution of aerosols, and hygroscopic growth for aerosol scattering. In Beijing city, the RH in autumn is high (Zhao et al., 2011), and biomass burning in the vicinity is prevalent due to autumn harvest (Wang et al., 2014). These special conditions may result in different formation mechanisms of haze in autumn.

In October 2014, four serious haze events occurred, which were some of the severest hazes in the NCP in the autumn period. The haze mainly influenced the NCP and the northeast China region, covering an area of $560000 \mathrm{~km}^{2}$. The largest concentrations of $\mathrm{PM}_{10}$ and $\mathrm{PM}_{2.5}$ were 741 and $508 \mathrm{~g} \mathrm{~m} \mathrm{~m}^{-3}$, which were recorded in Shijiazhuang, the capital of Hebei province. Until now, few studies have reported on this haze episode and its distinctive formation mechanism. In this study, comprehensive measurements were conducted from 5 October to 2 November in Beijing to investigate the characteristics and specific mechanism of continuous extreme hazes in the autumn. 


\section{Experiment}

\subsection{Experiment site}

Beijing is the capital of the People's Republic of China and the national center for politics, economics and culture. The GDP (gross domestic product) of Beijing in 2013 was 3.15 trillion dollars with a growth rate of $7.7 \%$. The population of Beijing was 21.15 million with a population density of 1289 people per $\mathrm{km}^{2}$ at the end of 2013 (http://www. bjstats.gov.cn/nj/main/2014-tjnj/CH/index.htm). There were 5.4 million cars, with a growth of 0.237 million cars in Beijing as of 2013 (http://zhengwu.beijing.gov.cn/tjxx/tjgb/ t1340447.htm). High population and economic levels have led to heavy emissions of air pollutants in Beijing.

Field measurements from 5 October to 2 January 2014 were performed at the urban atmospheric environment monitoring superstation $\left(39.96^{\circ} \mathrm{N}, 116.36^{\circ} \mathrm{E}\right)$ on the campus of Beijing Normal University (BNU). This site was located at the northern part of Beijing. The third ring road, one of the main traffic lines of Beijing, was approximately $300 \mathrm{~m}$ to the north of the measurement site. The observation site was on the roof of a 6-story building (approximately $20 \mathrm{~m}$ above ground level); all of the instruments except the visibility sensor were installed in an air-conditioned room. Mass concentration of gases was measured by the National Environmental Bureau on the Olympic Sports Center site $\left(39.98^{\circ} \mathrm{N}\right.$, $\left.116.39^{\circ} \mathrm{E}\right)$.

\subsection{Measurement and method}

The mass concentration of $\mathrm{PM}_{2.5}$ was measured by TEOM (tapered element oscillating microbalance, RP1405F) at the $\mathrm{BNU}$ site, whereas the mass concentration of gases $\left(\mathrm{SO}_{2}\right.$, $\mathrm{NO}_{2}, \mathrm{CO}$ and $\mathrm{O}_{3}$ ) was monitored by the National Environmental Bureau, and the data were gathered from the Internet (http://www.pm25.in/). We chose the data from the Olympic Sports Center site, since it was nearest to BNU site. Atmospheric visibility with range from $10 \mathrm{~m}$ to $80 \mathrm{~km}$ was measured by the visibility sensor (Belfort 6000) at the wavelength of $880 \mathrm{~nm}$ (Liu et al., 2013b), which consisted of a transmitter, a receiver, and a controller. The atmospheric extinction coefficient $b_{\text {ext }}(\mathrm{RH})$ at $550 \mathrm{~nm}$ in units of inverse megameter $\left(\mathrm{Mm}^{-1}\right)$ was calculated by Eq. (1) from the visibility data (Koschmieder, 1924):

$b_{\text {ext }}(\mathrm{RH})=\frac{3.912 \times 10^{3}}{\text { Vis }} \times\left(\frac{880}{550}\right)$.

The $\mathrm{BC}$ (black carbon) in $\mathrm{PM}_{2.5}$ was measured using an Aethalometer (Model AE33, Magee Scientific Corporation) with seven wavelengths from $370 \mathrm{~nm}$ (UV) to $950 \mathrm{~nm}$ (IR) and a time resolution of $5 \mathrm{~min}$. The aerosol absorption coefficient $b_{\text {ap }}$ was calculated using Eq. (2):

$b_{\text {ap }}=[\mathrm{BC}] \times 6.6 \times\left(\frac{\lambda}{550}\right)$.
The aerosol scattering coefficient at dry condition, $b_{\mathrm{sp}}$ (dry), was measured by integrating a nephelometer (Model Aurora 3000, Ecotech, Australia) with a desiccant before the inlet.

Thus, the aerosol scattering coefficient under ambient condition $b_{\mathrm{sp}}(\mathrm{RH})$ was calculated using Eq. (3):

$b_{\mathrm{sp}}(\mathrm{RH})=b_{\mathrm{ext}}(\mathrm{RH})-b_{\mathrm{ap}}-b_{\mathrm{ag}}-b_{\mathrm{sg}}$,

where $b_{\mathrm{ag}}$ was calculated using the experiential equation $b_{\mathrm{ag}}=\left[\mathrm{NO}_{2}\right] \times 0.33$ (Hodkinson, 1966) with the unit of $\mathrm{NO}_{2}$ being ppbv, and the scattering coefficient by gas, $b_{\mathrm{sg}}$, was assumed to be constant at a value of $10 \mathrm{Mm}^{-1}$ (Liu et al., 2008, 2013a).

The hygroscopic growth of aerosol scattering $f(\mathrm{RH})$, was widely used as the ratio of the aerosol scattering coefficient under wet conditions to that under dry conditions. It was calculated using Eq. (4) (Liu et al., 2008):

$f(\mathrm{RH})=\frac{b_{\mathrm{sp}}(\mathrm{RH})}{b_{\mathrm{sp}}(\mathrm{dry})}=\frac{b_{\mathrm{ext}}(\mathrm{RH})-b_{\mathrm{ap}}-b_{\mathrm{ag}}-b_{\mathrm{sg}}}{b_{\mathrm{sp}}(\mathrm{dry})}$

The single scattering albedo (SSA) is the ratio of the aerosol scattering coefficient over the aerosol extinction coefficient at a given wavelength. In this study, SSA was calculated with $b_{\text {sp }}(\mathrm{RH})$ and $b_{\text {ap }}$ via Eq. (5):

$\mathrm{SSA}=\frac{b_{\mathrm{sp}}(\mathrm{RH})}{b_{\mathrm{sp}}(\mathrm{RH})+b_{\mathrm{ap}}}$

The meteorological station (Vaisala, Finland) monitored solar radiation, wind direction, wind speed and relative humidity. The height of the PBL, the wind field graph and atmospheric back trajectories were obtained from the ARL (Air Resources Laboratory) at the NOAA website (http:// www.arl.noaa.gov/index.php). Meteorological data from the GDAS (Global Data Assimilation System) was used for the model calculation.

The NR-PM 1 (non-refractory submicron aerosol) species, including organics, $\mathrm{SO}_{4}^{2-}, \mathrm{NO}_{3}^{-}, \mathrm{NH}_{4}^{+}$and $\mathrm{Cl}^{-}$, were measured in situ using an ACSM (aerosol chemical speciation monitor) with an air flow of $0.1 \mathrm{~L} \mathrm{~min}^{-1}$ and a time resolution of $15 \mathrm{~min}$. More detailed operations and calibrations of the ACSM can be found in the work of Sun et al. (2013). The instruments involved in this study were listed in Table 1.

\section{Results and discussion}

\subsection{Characteristics of the haze episodes}

\subsubsection{Overall description}

As illustrated in Fig. 2, there were four haze episodes during the field measurement in Beijing, which were 7 to 11 October, 17 to 20 October, 22 to 26 October, and 29 October to 1 November.

The highest concentration of $\mathrm{PM}_{2.5}$ occurred at 18:00 on 25 October (the third episode), with a value of $469 \mu \mathrm{g} \mathrm{m}^{-3}$. 
Table 1. Overview of the instruments involved in this study.

\begin{tabular}{|c|c|c|c|}
\hline Instrument & Parameter & Manufacturer & Model \\
\hline TEOM & $\mathrm{PM}_{2.5}$ & \multicolumn{2}{|c|}{ Thermo. Electron., RP1405F } \\
\hline Visibility meter & Visibility & \multicolumn{2}{|c|}{ Belfort 6000} \\
\hline Aethalometer & $\mathrm{BC}$ & \multicolumn{2}{|l|}{ AE33 } \\
\hline Integrating nephelometer & Aerosol scattering coefficient & \multicolumn{2}{|l|}{ Ecotech, Aurora 3000} \\
\hline Wind speed/Temperature/RH sensor & Wind speed, Temperature, $\mathrm{RH}$ & Vaisala GMT220 & HMP45 \\
\hline ACSM & The NR-PM 1 species & - & \\
\hline
\end{tabular}
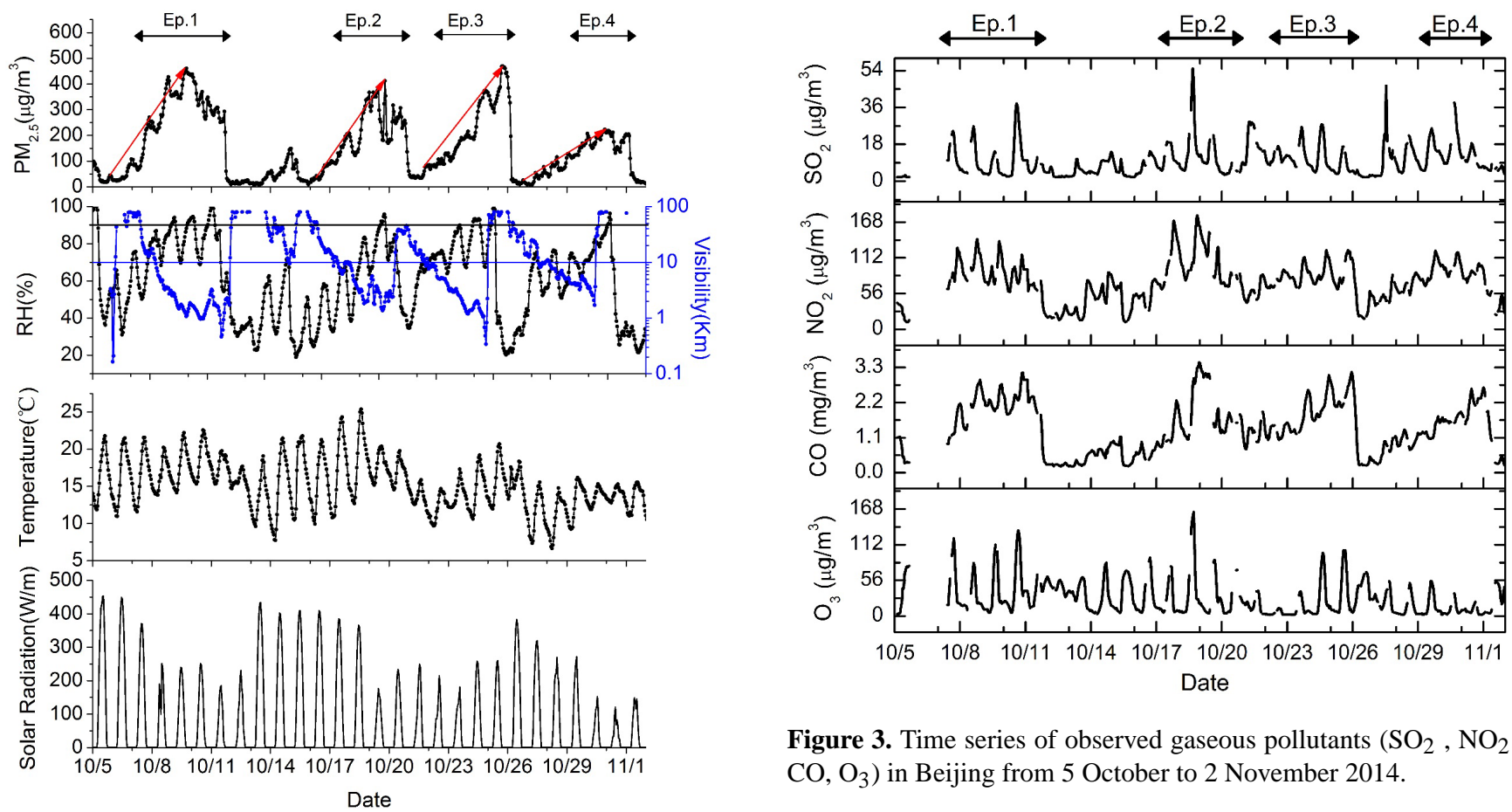

Figure 3. Time series of observed gaseous pollutants $\left(\mathrm{SO}_{2}, \mathrm{NO}_{2}\right.$, $\mathrm{CO}, \mathrm{O}_{3}$ ) in Beijing from 5 October to 2 November 2014.

Figure 2. Time series of observed $\mathrm{PM}_{2.5}$, RH, temperature and solar radiation in Beijing from 5 October to 2 November 2014.

Although the haze was severe, the peak value was much lower than that $\left(900 \mu \mathrm{g} \mathrm{m}^{-3}\right)$ during the haze in January 2013 (Zhang et al., 2014). Before the peak, increasing $\mathrm{PM}_{2.5}$ concentrations were observed. The four episodes had similar accumulation and dispersion patterns, in which the increasing slopes for the $\mathrm{PM}_{2.5}$ values in four episodes resembled each other, and the pollutants were dispersed within a few hours. The rates of increase of $\mathrm{PM}_{2.5}$, which were represented by the slope of $\mathrm{PM}_{2.5}$ concentrations, were calculated. To reduce the influence of the diurnal variation of $\mathrm{PM}_{2.5}$, the first and last peak values in each haze episode were chosen in the calculation. Thus, the slope $r$ was

$r\left(\mathrm{PM}_{2.5}, \mu \mathrm{g} \mathrm{m}^{-3} \mathrm{~h}^{-1}\right)=\frac{\left[\mathrm{PM}_{2.5}\right]_{\max }-\left[\mathrm{PM}_{2.5}\right]_{\min }}{T \text { (hour) }}$.

The results were shown in Table 2 . 
Table 2. The slopes of $\mathrm{PM}_{2.5}$ concentrations during the four haze episodes $\left(\mu \mathrm{g} \mathrm{m}^{-3} \mathrm{~h}^{-1}\right)$.

\begin{tabular}{ccccc}
\hline & $\begin{array}{c}\text { Episode 1 } \\
\left(\mu \mathrm{g} \mathrm{m}^{-3} \mathrm{~h}^{-1}\right)\end{array}$ & $\begin{array}{c}\text { Episode 2 } \\
\left(\mu \mathrm{g} \mathrm{m}^{-3} \mathrm{~h}^{-1}\right)\end{array}$ & $\begin{array}{c}\text { Episode 3 } \\
\left(\mu \mathrm{g} \mathrm{m}^{-3} \mathrm{~h}^{-1}\right)\end{array}$ & $\begin{array}{c}\text { Episode 4 } \\
\left(\mu \mathrm{g} \mathrm{m}^{-3} \mathrm{~h}^{-1}\right)\end{array}$ \\
\hline$r\left(\mathrm{PM}_{2.5}\right)$ & 4.03 & 4.44 & 4.16 & 2.00 \\
\hline
\end{tabular}

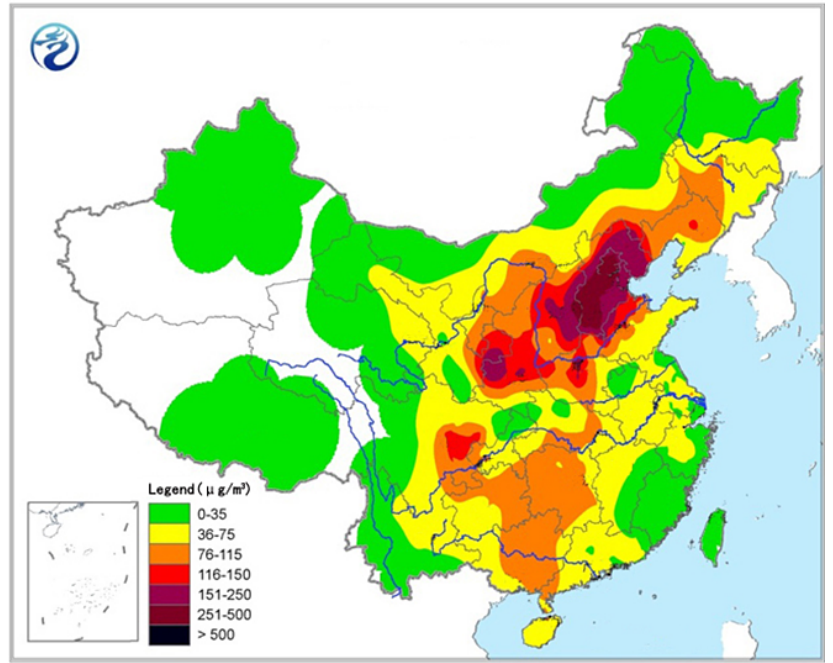

Figure 4. Spatial distribution of the $\mathrm{PM}_{2.5}$ concentration over China from 5:00 a.m. 9 October to 5:00 a.m. 10 October (from China Meteorological Administration, http://www.nmc.gov. $\mathrm{cn} /$ publish/observations/environmental.htm).

on 30 and 31 October, whereas $\mathrm{PM}_{2.5}$ and other gaseous pollutants reached their peaks at this time, which indicated that the photochemical reaction during the fourth episode was not strong and that heterogeneous reactions played a major role in the haze formation in the fourth episode. All of the gaseous pollutants showed daily variation and reached a maximum on 18 October. These were also related to the variance in the height of the PBL, which will be discussed in Sect. 3.2.4.

Like the other severe hazes (Tao et al., 2014a, b) in last 2 years, the haze in October 2014 also influenced China to a large extent (Fig. 4). According to the $\mathrm{PM}_{2.5}$ spatial distribution over China, the haze originated from the North China Plain (NCP) and developed in the southwest and northeast directions. A similar situation occurred in September 2011, when the haze originated from Beijing and developed in the same directions (Liu et al., 2013b). Moreover, the haze influenced a large area of middle China and northeastern China; for example, the concentration of $\mathrm{PM}_{2.5}$ in Harbin, which is a large city in northeastern China, peaked at $664 \mu \mathrm{g} \mathrm{m}^{-3}$ during the third haze episode.

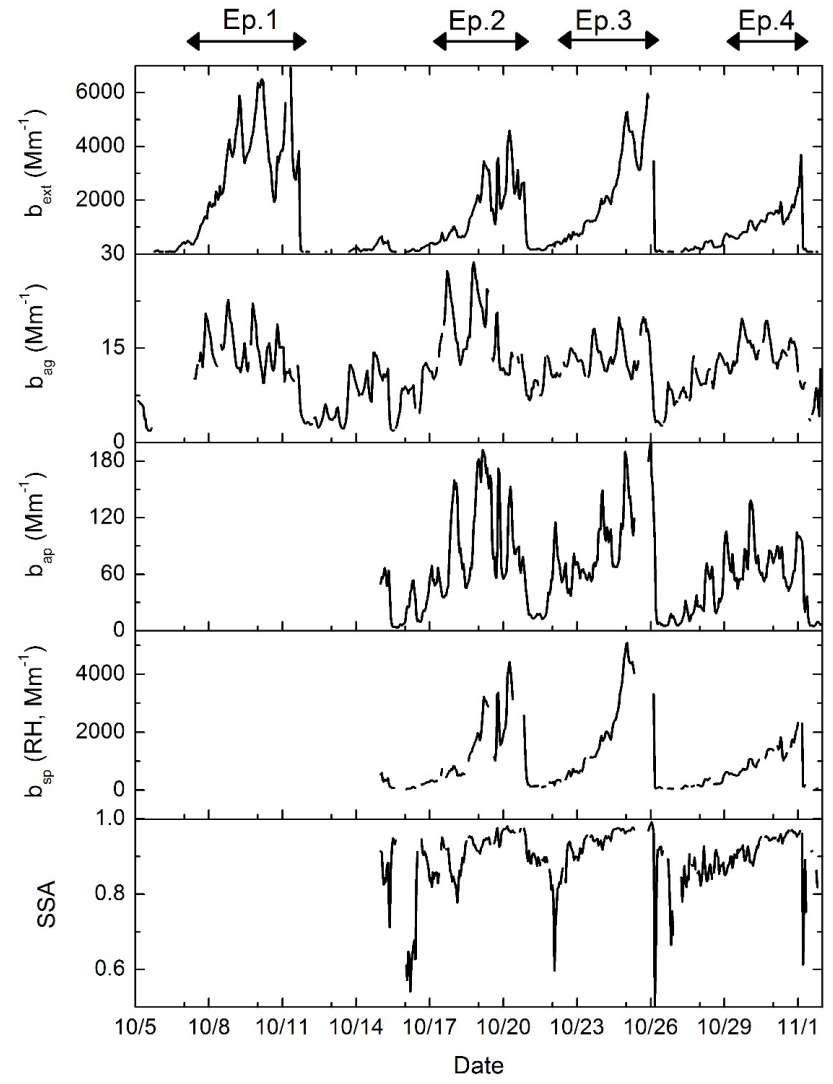

Figure 5. Time series of the atmospheric extinction coefficient $b_{\text {ext }}$, absorption by $\mathrm{NO}_{2}$ coefficient $b_{\mathrm{ag}}$, aerosol absorption coefficient $b_{\text {ap }}$, ambient aerosol scattering coefficient $b_{\text {sp }}(\mathrm{RH})$, and single scattering albedo (SSA) in Beijing from 5 October to 2 November 2014.

\subsubsection{Optical properties}

The temporal variation of the aerosol scattering coefficient at ambient environment $b_{\mathrm{sp}}(\mathrm{RH})$, the absorption coefficient by $\mathrm{NO}_{2} b_{\text {ag }}$, the aerosol absorption coefficient $b_{\text {ap }}$, the atmospheric extinction coefficient at ambient environment $b_{\text {ext }}(\mathrm{RH})$ and the SSA were shown in Fig. 5. Data for $b_{\text {ext }}(\mathrm{RH})$ were complete for the whole observation period, whereas the other three parameters were not available until 15 October. With clear diurnal variation, $b_{\mathrm{sp}}, b_{\mathrm{ap}}$ and $b_{\text {ext }}$ increased day by day during the haze episodes and decreased sharply at the end of these haze episodes. Because $b_{\mathrm{sp}}(\mathrm{RH})$ was calculated using $b_{\text {ap }}$ and $b_{\text {ext }}$ and $b_{\text {ap }}$ was relatively small compared to $b_{\mathrm{ext}}$, the $b_{\mathrm{sp}}(\mathrm{RH})$ had nearly the 
a)

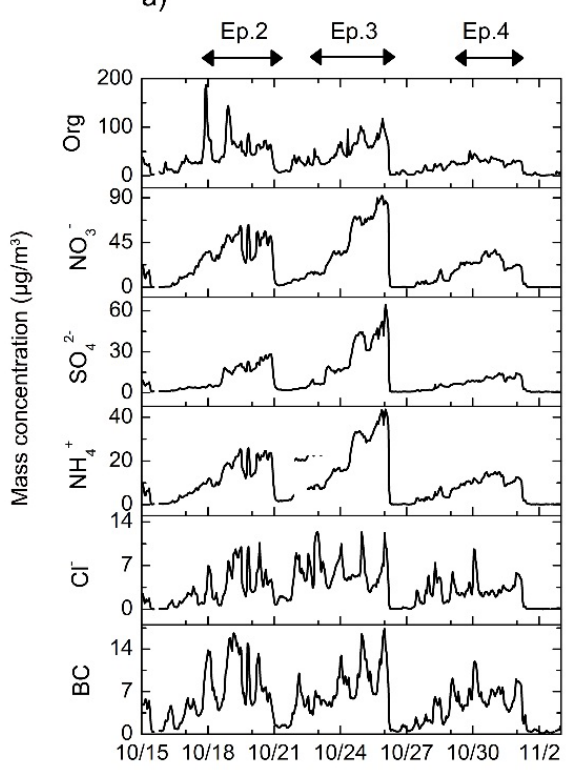

b)

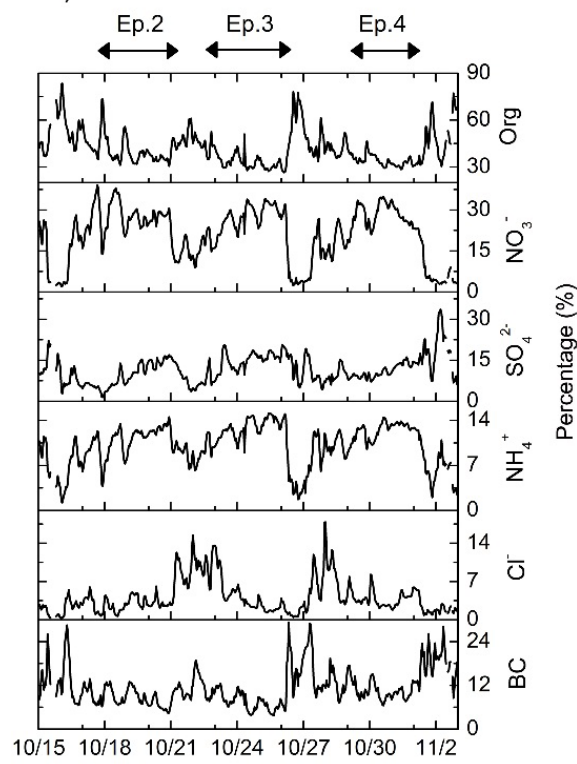

c)

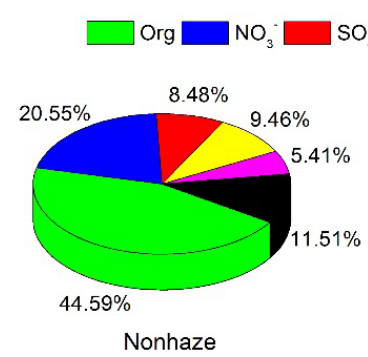

$\mathrm{O}_{4}^{2 .} \square \mathrm{NH}_{4}^{+} \square \mathrm{Cl} \square \mathrm{BC}$

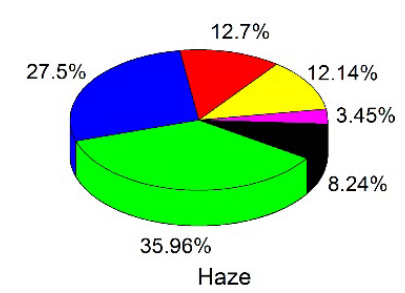

Figure 6. (a) Temporal variation of the mass concentration of each aerosol species in $\mathrm{PM}_{1}$, (b) temporal variation of the mass fraction of each aerosol species in $\mathrm{PM}_{1}$, (c) mass fraction of each aerosol species in $\mathrm{PM}_{1}$ during non-haze and haze episodes from 15 October to 2 November 2014.

same temporal variation as $b_{\text {ext }}$. The maximum $b_{\text {ext }}$ was $5611 \mathrm{Mm}^{-1}$ at 22:00 on 25 October, and the average $b_{\text {ext }}$ reached $1069 \mathrm{Mm}^{-1}$. Both data were much higher than those of other studies (Garland et al., 2008; Jung et al., 2009). The SSA in Fig. 5 was calculated with the aerosol extinction at ambient environment coefficient, $b_{\mathrm{sp}}(\mathrm{RH})$. Aerosol representing fresh emission always has a low SSA, whereas aged aerosol has a higher SSA (Garland et al., 2008). As a result, the SSA showed an increasing trend during the haze episodes. Four sudden decreases in the SSA were observed during the dawn of 16,22 , and 26 October and 1 November. The first two decreases occurred at the beginning of haze episodes, which represented large quantities of freshly emitted aerosol. Since local emissions in Beijing showed a steadier pattern, the sudden change in SSA indicated pollutant transport from the vicinity of Beijing (discussed in Sect. 3.2.2). The other two decreases occurred at the end of haze episodes when strong winds blew over Beijing, and the pollutants were largely removed (discussed in Sect. 3.2.3). Aged aerosol was cleared and new aerosols increased in a short time (Guo et al., 2014). Thus, SSA decreased sharply.

\subsection{Formation mechanism of haze episodes}

\subsubsection{Secondary transformation of aerosols}

Water-soluble ions are a primary component of aerosols and play a major role in the hygroscopic growth of aerosols. The temporal variations of major components (organic matter, $\mathrm{SO}_{4}^{2-}, \mathrm{NO}_{3}^{-}, \mathrm{NH}_{4}^{+}, \mathrm{Cl}^{-}$and black carbon (BC)) in $\mathrm{PM}_{1}$ were shown in Fig. 6. Organic matter contributed most to the $\mathrm{PM}_{1}$, followed by $\mathrm{NO}_{3}^{-}, \mathrm{SO}_{4}^{2-}, \mathrm{NH}_{4}^{+}, \mathrm{BC}$ and $\mathrm{Cl}^{-}$. The mass concentration of $\mathrm{SO}_{4}^{2-}$ was always higher than that of $\mathrm{NO}_{3}^{-}$, especially in the winter time, when the heat supply was prevalent in northern China (Zhao et al., 2013). Although Beijing was replacing coal with natural gas for a heat supply, the influence from the vicinity was still enormous. However, in this study, the mass concentration of $\mathrm{NO}_{3}^{-}$was always higher than that of $\mathrm{SO}_{4}^{2-}$. The concentration of $\mathrm{NO}_{3}^{-}$, which was primarily transferred from $\mathrm{NO}_{x}$, represented the contribution of motor vehicle sources. The heat supply was not available during October in the NCP, and the motor vehicles remained at a similar level throughout the year, which 
implied that motor vehicles played a more important part in the hazes during autumn. During the haze periods, the percentage of $\mathrm{NO}_{3}^{-}$and $\mathrm{NH}_{4}^{+}$increased, whereas the percentage of organic matter continued to decrease. When strong wind blew pollutants away, the percentage of organic matter increased sharply. On the contrary, the percentage of $\mathrm{NO}_{3}^{-}$decreased in a short time and did not return for a certain time. $\mathrm{SO}_{4}^{2-}$ varied similarly to $\mathrm{NO}_{3}^{-}$but in a much milder pattern. After the strong wind, even the concentration of $\mathrm{SO}_{4}^{2-}$ decreased, and the return time was much shorter than that of $\mathrm{NO}_{3}^{-}$. This indicated that even though the concentration of $\mathrm{SO}_{4}^{2-}$ was lower than that of $\mathrm{NO}_{3}^{-}$, the oxidation rate from $\mathrm{SO}_{2}$ to $\mathrm{SO}_{4}^{2-}$ was faster. It has been reported that the existence of high levels of $\mathrm{NO}_{x}$ might accelerate the reaction from $\mathrm{SO}_{2}$ to $\mathrm{SO}_{4}^{2-}$ (He et al., 2014).

Even though all of the components in $\mathrm{PM}_{1}$ increased during the haze events, the accumulation pattern might be different for each component. Comparatively, the increasing pattern of SNA (sulfate, nitrate, and ammonium) was likely from local emissions. Diurnal variation of the concentration of SNA also existed, but it was not as significant as that of organic matter, $\mathrm{Cl}^{-}$and $\mathrm{BC}$. There was also no sudden increase in the concentrations of SNA. They were more likely to accumulate stably with high RH and a stagnant atmosphere. When the RH was high and the atmosphere was stable, gases such as $\mathrm{SO}_{2}$ and $\mathrm{NO}_{x}$ transform to SNA at a fast rate. A clear increase in the SNA percentage could be seen in the pie charts in Fig. 6. The values for $\mathrm{SO}_{4}^{2-}, \mathrm{NO}_{3}^{-}$and $\mathrm{NH}_{4}^{+}$in $\mathrm{PM}_{1}$ increased from 8.48, 20.55 and $9.46 \%$ in the non-haze period to $12.7,27.5$ and $12.14 \%$ in the haze episode, respectively. Continuous increasing of SNA indicated that the formation of new SNA during the haze episodes contributed most of the formation of the haze. During the hazes in January 2013, high conversions from the gas phase of $\mathrm{SO}_{2}$ and $\mathrm{NO}_{x}$ to the particle phase of $\mathrm{SO}_{4}^{2-}$ and $\mathrm{NO}_{3}^{-}$were found, and heterogeneous formations of $\mathrm{SO}_{4}^{2-}$ and $\mathrm{NO}_{3}^{-}$were considered to be important, especially during low visibility episodes (Quan et al., 2014).

SOR (sulfur oxidation ratios) and NOR (nitrogen oxidation ratios) were important factors, showing that gaseous species would be oxidized to secondary aerosols in the atmosphere (Sun et al., 2006). They were widely used in the analysis of the secondary transformation of aerosols. $\mathrm{PM}_{2.5}$ and SOR, NOR were highly related. As we found in the Fig. S1 in the Supplement, $\mathrm{PM}_{2.5}$ was well fitted with SOR and NOR. The correlation coefficient was 0.62 between $\mathrm{PM}_{2.5}$ and SOR and 0.79 between $\mathrm{PM}_{2.5}$ and NOR. It meant SOR and NOR could be higher with higher concentration of $\mathrm{PM}_{2.5}$. The temporal variations of SOR and NOR were shown in Fig. 7. SOR was mostly higher than 0.2 , and NOR was mostly higher than 0.1 , indicating intense secondary formation of $\mathrm{SO}_{4}^{2-}$ and $\mathrm{NO}_{3}^{-}$(Fu et al., 2008). SOR and NOR increased during the haze episodes with accumulated pollutants. Furthermore, SOR increased more quickly than NOR. To compare the rate

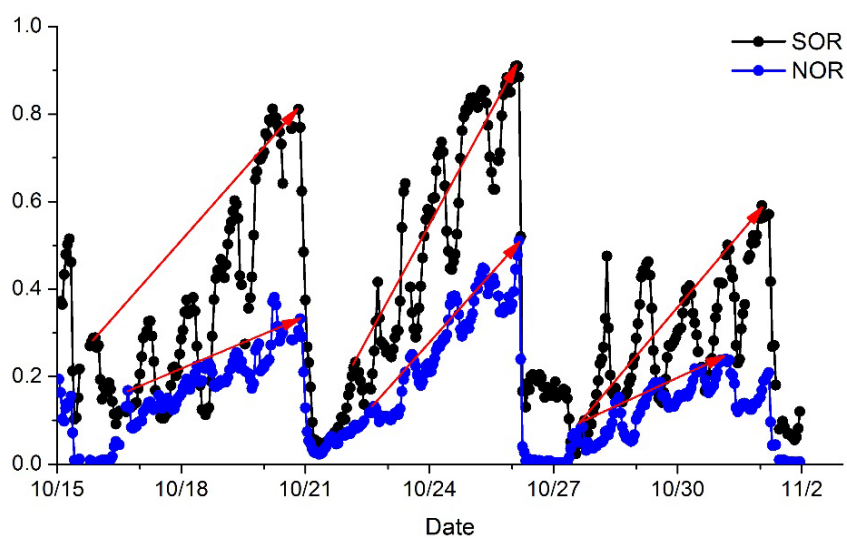

Figure 7. Time series of SOR (sulfate oxidation rate) and NOR (nitrate oxidation rate) from 15 October to 2 November 2014.

of increase of SOR and NOR, the slope of the SOR and NOR in the observed haze were calculated. To reduce the influence of the diurnal variation of SOR and NOR, the first and last peak values in the figure were chosen in the calculation. Thus, the slope $r$ was

$r\left(\mathrm{SOR}, \mathrm{h}^{-1}\right)=\frac{\mathrm{SOR}_{\max }-\mathrm{SOR}_{\min }}{T \text { (hour) }}$.

$r\left(\mathrm{NOR}, \mathrm{h}^{-1}\right)=\frac{\mathrm{NOR}_{\max }-\mathrm{NOR}_{\min }}{T \text { (hour) }}$.

The results were shown in Table 3 .

In the three observed haze episodes, $\mathrm{r}(\mathrm{SOR})$ was $3.4,1.6$, and 4.2 times of $r$ (NOR), which indicated faster production of $\mathrm{SO}_{4}^{2-}$, even though the concentration of $\mathrm{SO}_{4}^{2-}$ was lower than that of $\mathrm{NO}_{3}^{-}$. Meanwhile, after the strong wind, which decreased SOR and NOR sharply, low SOR still existed, whereas NOR was nearly 0 . These findings explained the shorter return time of $\mathrm{SO}_{4}^{2-}$ after the haze episodes.

\subsubsection{Combustion of biomass and regional transport}

Biomass burning became prevalent in the NCP during the autumn harvest. The combustion was primarily conducted in the open field. Pollutants, such as BC and CO, were emitted on a large scale and influenced the air quality not only in the emission region but also in the downstream city. Hence, biomass burning in the surrounding provinces was an important cause of the hazes in the autumn in Beijing. Fire points in China, based on data from MODIS Terra and Aqua satellites, on 6 October were shown in Fig. 8a. On 6 October, 267 fire points were found in China, among which 29, 163 and 30 fire points were found in Hebei, Henan and Shandong provinces, respectively. In total, 1957 fire points, which were caused by biomass burning in the whole of October, were found in China, among which 54, 26 and 57 fire points 
a)

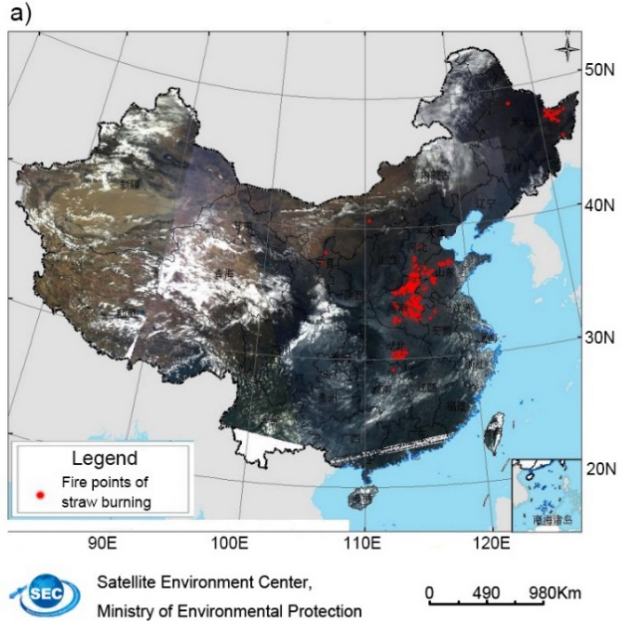

b)

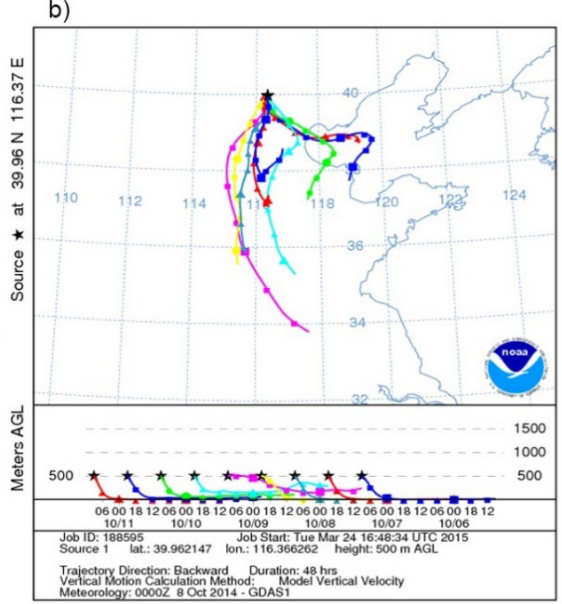

Figure 8. (a) Fire points of straw burning over China on 6 October 2014, (b) Backward trajectories from Beijing for Episode 1.

Table 3. The slopes of SOR and NOR during three haze episodes.

\begin{tabular}{lccc}
\hline & $\begin{array}{c}\text { Episode 2 } \\
\left(\mathrm{h}^{-1}\right)\end{array}$ & $\begin{array}{c}\text { Episode 3 } \\
\left(\mathrm{h}^{-1}\right)\end{array}$ & $\begin{array}{c}\text { Episode 4 } \\
\left(\mathrm{h}^{-1}\right)\end{array}$ \\
\hline$r(\mathrm{SOR})$ & $5.63 \times 10^{-3}$ & $7.05 \times 10^{-3}$ & $6.22 \times 10^{-3}$ \\
$r(\mathrm{NOR})$ & $1.64 \times 10^{-3}$ & $4.5 \times 10^{-3}$ & $1.49 \times 10^{-3}$ \\
\hline
\end{tabular}

were found in Hebei, Henan and Shandong provinces, respectively. Although the fire points were more strictly controlled in 2014 compared to 2013, the influence of biomass burning still could not be neglected.

The backward trajectories of Beijing during the first haze episode reflected how the biomass burning influenced Beijing (Fig. 8b). A total of nine backward trajectories of $48 \mathrm{~h}$ were drawn with the HYSPLIT model online version. The backward trajectories started from 17:00 (LST) on 11 October and restarted a new trajectory every $12 \mathrm{~h}$. The air mass during the first haze episode mainly came from the south and southeast, originating from Hebei, Henan, Shandong and even Anhui Province. The pollutants from biomass burning in these provinces were transported to Beijing. Once the meteorological conditions were stagnant, haze formed and was aggravated in this region. A similar situation occurred in the haze in 2007 ( $\mathrm{Li}$ et al., 2010). Therefore, biomass burning was a tough challenge for air pollution control in the autumn.

Based on the temporal variation of each component in Fig. 6, the organic matter, $\mathrm{Cl}^{-}$and $\mathrm{BC}$ had similar variation patterns. In addition to clear diurnal variations, which were caused by the diurnal development of the PBL, a sudden increase before each haze period was found for the concentration of organic matter, $\mathrm{Cl}^{-}$and $\mathrm{BC}$. On 18 October, the height of the PBL $(468.7 \mathrm{~m})$ was $21.1 \%$ higher than that on 17 October $(386.9 \mathrm{~m})$, but the concentrations of organic matter, $\mathrm{Cl}^{-}$and $\mathrm{BC}$ were 6,6 and 4 times the values of the day before. Organic matter, $\mathrm{Cl}^{-}$and $\mathrm{BC}$ were emitted from biomass burning; abnormal high values and a sudden increase in organic matter, $\mathrm{Cl}^{-}$and $\mathrm{BC}$ indicated spatial transport of pollutants from straw burning. Consequently, regional pollutant transport was important for haze formation in October 2014, and straw burning was a significant pollution source. However, the concentrations of organic matter, $\mathrm{BC}$ and $\mathrm{Cl}^{-}$in haze period were found lower than those in nonhaze period. It was because the increase of organic matter, $\mathrm{BC}$ and $\mathrm{Cl}^{-}$was obvious in the beginning part of haze, after which the increase of new SNA were predominant.

\subsubsection{Stationary synoptic condition}

Pressure systems can influence the wind and precipitation of a region. Surface weather maps of East Asia at 02:00 (LST) on 7-10 October during the first haze episode were shown in Fig. 9. The NCP was dominated by a weak high-pressure system on 7 October, which lasted for the following 2 days. The weak high-pressure system resulted in low surface wind and relatively stagnant weather, which was unfavorable for the dispersion of air pollutants. The high-pressure system slowly moved towards the northeast. Meanwhile, the Mongolia anticyclone (a low-pressure system) moved towards and encountered the high-pressure system on 9 October, which brought wind and caused a small decrease in $\mathrm{PM}_{2.5}$ on the dawn of 9 October. However, the weak high-pressure system dominated the NCP on 10 October, and the weather became stagnant again until 11 October, when another strong Mongolia anticyclone moved to the NCP, and the first haze episode ended.

The wind fields at 02:00 on 10,20,24, and 31 October in the NCP region were shown in Fig. 10, representing typical days in the four haze episodes. Generally, the wind speeds were slow during the haze episodes. In addition, the wind slowed sharply around Beijing city in all four figures. For example, on 31 October, the wind over the NCP came from 

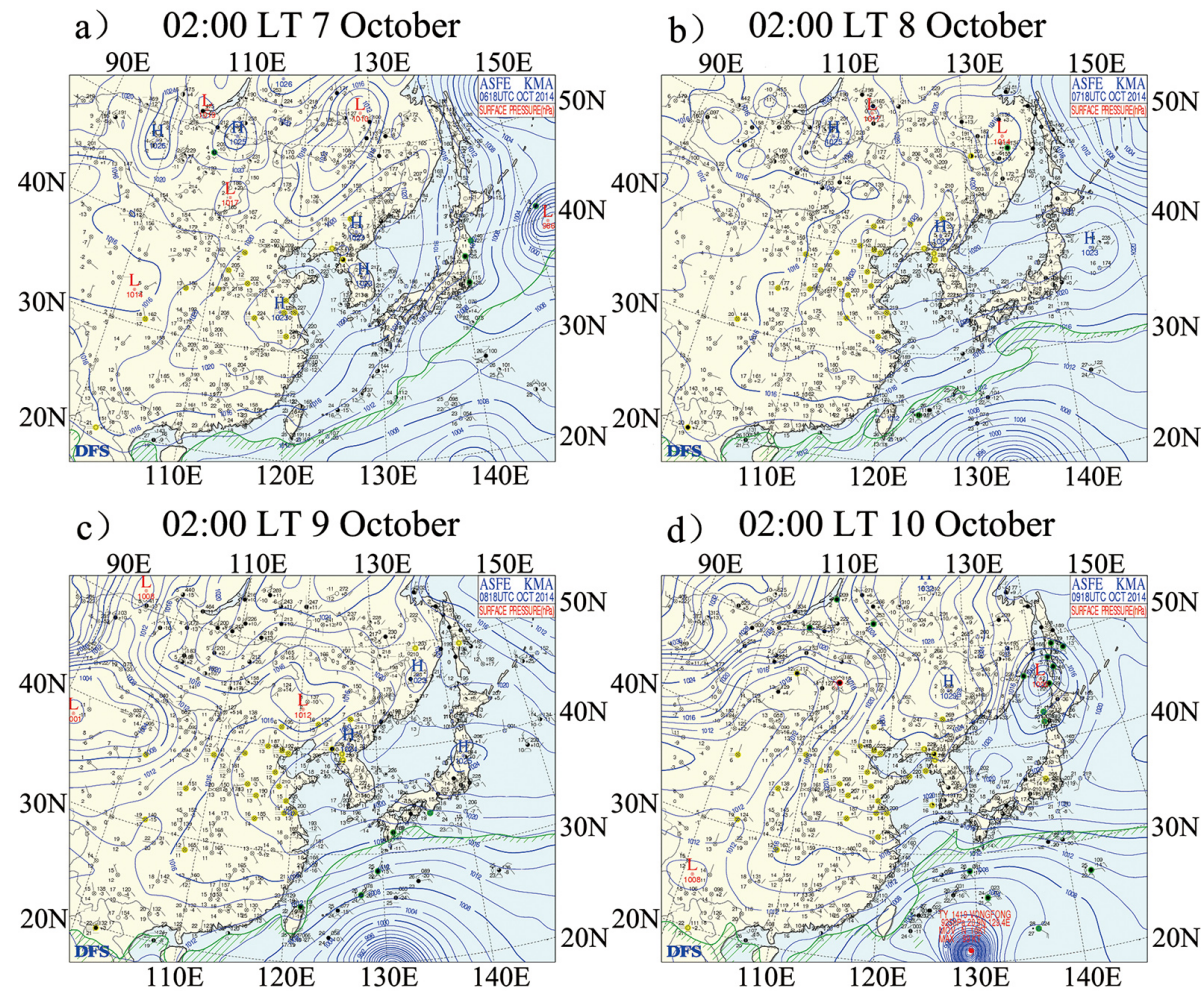

Figure 9. Surface pressure on the surface at (a) 02:00 LST 7 October, (b) 02:00 LST 8 October, (c) 02:00 LST 9 October, and (d) 02:00 LST 10 October.

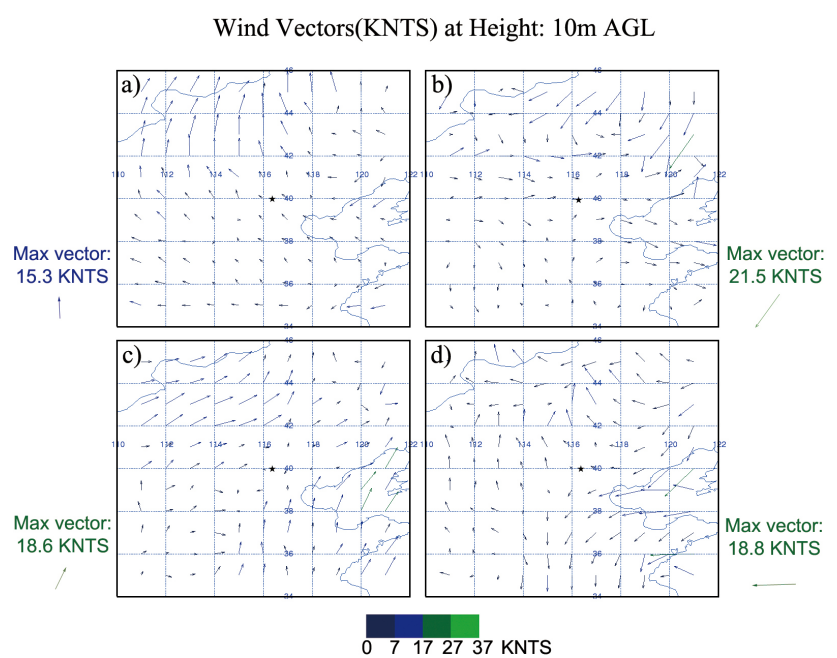

Figure 10. Wind field graphs of the NCP at (a) 02:00 LST 10 October, (b) 02:00 LST 20 October, (c) 02:00 LST 24 October, and (d) 02:00 LST 31 October; black star denotes Beijing city, the color bar represents wind vectors.

the east, from the Bohai Sea. The wind separated into two directions when it encountered Beijing, one blowing to the north and the other blowing to the south. The wind over Beijing maintained a low speed. A similar phenomenon was ob- served in January 2013 when a severe haze occurred in Beijing (Tao et al., 2014b). Moreover, the wind on 10 October was smooth, blowing from the southeast of Beijing and then turning to the northeast. The wind around Beijing was clearly slowed and became strong after blowing over Beijing. The city acted as a large obstacle for the wind, slowing the wind speed, disturbing the wind direction and affecting other properties of the wind (Miao et al., 2009). The wind on 20 October was more complex. Winds from the southwest and the northwest blew toward and converged at Beijing. The winds from the two directions weakened each other, creating stagnant conditions in Beijing. The pollutants in the vicinity were brought to Beijing, accumulating and reacting further (Zhao et al., 2013). On 24 October, the wind was similar to that on 10 October, with the exception of the disordered directions around Beijing city.

Changes in wind pattern influenced the near-surface aerosol concentration (Pal et al, 2014). The wind rose diagram overlaid with the $\mathrm{PM}_{2.5}$ concentrations from 5 October to 2 November were shown in Fig. 11. The winds blew mainly from three directions: northwest, northeast, and southwest. In each direction, the higher the wind speeds were, the lower the $\mathrm{PM}_{2.5}$ concentrations were. The average wind speed was $1.1 \mathrm{~m} \mathrm{~s}^{-1}$, which was slightly higher than that $\left(0.9 \mathrm{~m} \mathrm{~s}^{-1}\right)$ in September 2011, when another haze episode occurred (Liu et al., 2013b). Furthermore, the $\mathrm{PM}_{2.5}$ 


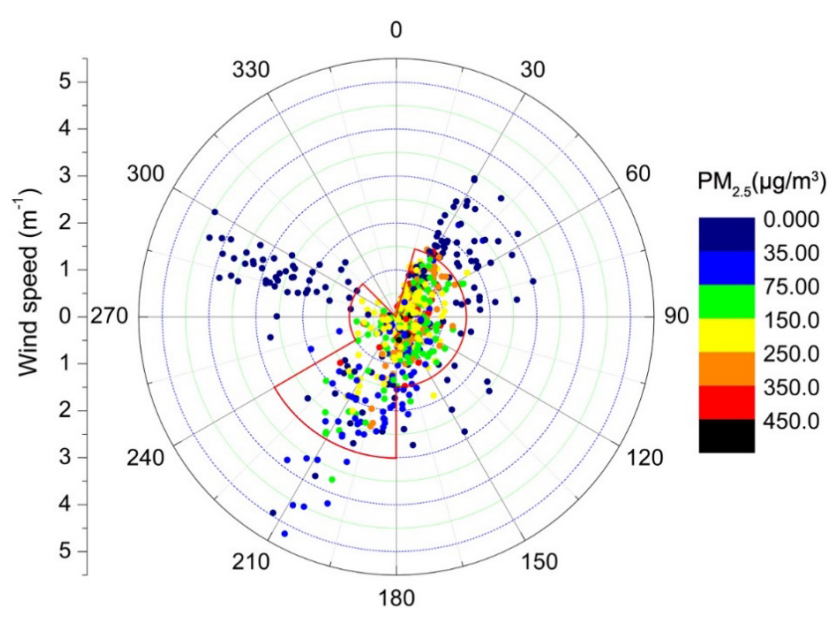

Figure 11. Wind rose diagrams of $\mathrm{PM}_{2.5}$ in Beijing in October 2014.

concentrations were relatively high within the wind speed limit: $1 \mathrm{~m} \mathrm{~s}^{-1}$ for wind from the northwest, $1.5 \mathrm{~m} \mathrm{~s}^{-1}$ for wind from the northeast and $3 \mathrm{~m} \mathrm{~s}^{-1}$ for wind from the southwest. For example, when the wind was from the northeast and the wind speed was lower than $1.5 \mathrm{~m} \mathrm{~s}^{-1}$, nearly all of the $\mathrm{PM}_{2.5}$ concentrations exceeded $75 \mu \mathrm{g} \mathrm{m}^{-3}$ (the national secondary standard of $\mathrm{PM}_{2.5}$ ) and vice versa. Nevertheless, when the wind blew northwest, with wind directions concentrating between 270 to $315^{\circ}$, the wind speed limit decreased to $1 \mathrm{~m} \mathrm{~s}^{-1}$. Thus, with similar wind speeds, the concentration of $\mathrm{PM}_{2.5}$ was lower. Zhang et al. (2015) made a research on relationships of evolution of $\mathrm{PM}_{2.5}$ concentrations and meteorological conditions. In Beijing city, winds from the northeast and southwest would result in higher concentration of $\mathrm{PM}_{2.5}$, and winds from the northeast would lead to the lowest recorded concentration of $\mathrm{PM}_{2.5}$ in autumn and winter. It could also be clearly found in the haze during January 2013 in Beijing (Yang et al., 2015). However, winds in January 2013 distributed more equally in every direction, while winds in October 2014 were concentrated in a specific direction. Differences between every wind direction were less in January 2013. High concentration (over $75 \mu \mathrm{g} \mathrm{m}^{-3}$ ) of $\mathrm{PM}_{2.5}$ could also be found at wind speeds over $2 \mathrm{~m} \mathrm{~s}^{-1}$ when wind blowing northwest.

\subsubsection{Variance of the PBL height}

The development of the PBL, which is mainly influenced by air temperature and dynamics, affects the vertical dispersion of pollutants (Pal et al., 2015). When the PBL height is low, the pollutants stay at the surface layer and maintain a higher level. This can easily lead to haze formation on the ground. As depicted in Fig. 12, the heights of the PBL between the two haze episodes were relatively high, and distinct descents of the PBL height were found during the four haze episodes. The lowest PBL at noon was $384 \mathrm{~m}$ on 17 Oc-

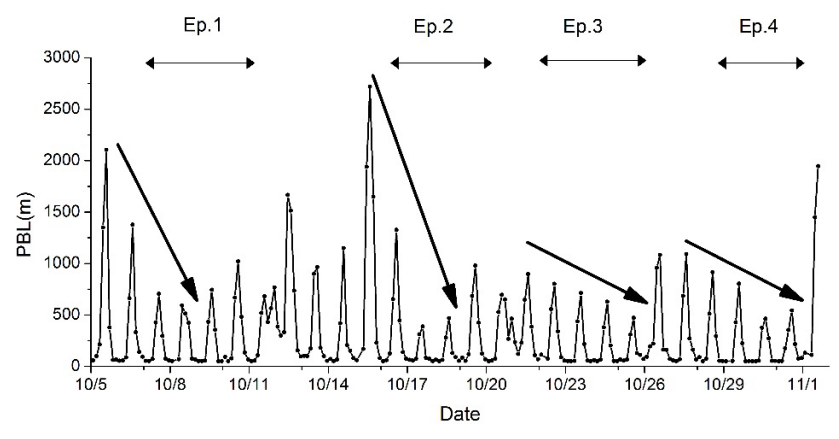

Figure 12. Time series of the PBL (planetary boundary layer) from 5 October to 2 November 2014.

tober. It was only $14 \%$ of the PBL height before the haze ( $2718 \mathrm{~m}$ on 15 October). Because it was difficult to break through the PBL, the local pollutants were compressed and accumulated near the surface, leading to a high concentration of $\mathrm{PM}_{2.5}$. This was not similar to cases reported in other haze episodes (Yang et al., 2015). The temperature during each haze episode in October 2014 maintained a constant level or even increased (Fig. 2). Normally, a higher temperature, which will enhance the PBL development, is conducive to higher PBL. However, the formation of hazes in October 2014 was influenced by many factors. The dynamics of the atmosphere is another important factor from the local perspective. The deficiency of horizontal movement of the atmosphere affected the vertical development of the PBL. The highest PBL occurred on 16 October, when a cold and fast wind blew over Beijing. The cold and fast air mass from Mongolia was an effective removal mechanism of the haze not only in the horizontal direction but also in the vertical direction. Once the cold air from the northwest blew over the $\mathrm{NCP}$, it not only promoted the horizontal dispersion of pollutants but also accelerated the vertical diffusion of pollutants because the height of the PBL was rapidly increased.

\subsubsection{Impact of the relative humidity on haze}

Four haze episodes in October 2014 were characterized by higher RH. The RH was over $90 \%$ during the severest haze period, and it sometimes reached $100 \%$ in October 2014. The high RH aggravated the haze.

The relationships between $\mathrm{RH}$ and SOR and between $\mathrm{RH}$ and NOR were illustrated in Fig. 13. SOR and NOR were highly correlated with RH. The correlation coefficients of SOR and NOR with RH were 0.79 and 0.55 , respectively, which were much higher than those in a previous study (Han et al., 2014), indicating the particularly high importance of $\mathrm{RH}$ during the haze episodes in this study. SOR reached a minimum when RH was approximately $40 \%$. When RH was $>40 \%$, SOR increased with increasing RH, whereas SOR decreased with increasing $\mathrm{RH}$ when $\mathrm{RH}$ was $<40 \%$. The conversion from $\mathrm{SO}_{2}$ to $\mathrm{SO}_{4}^{2-}$ requires water vapor as a re- 

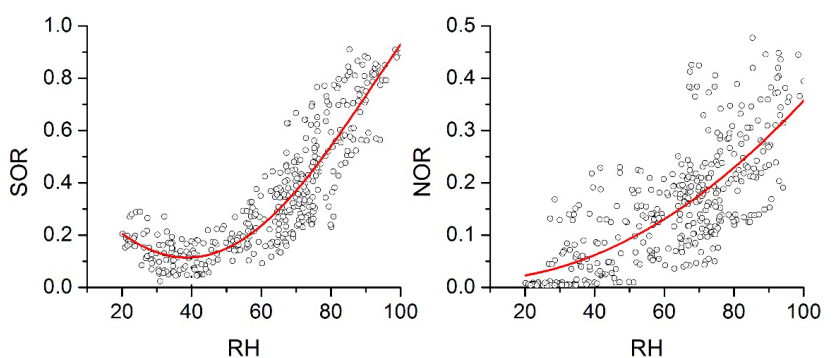

Figure 13. Relationship between RH (\%) and SOR and between RH $(\%)$ and NOR during the haze episodes in October 2014.

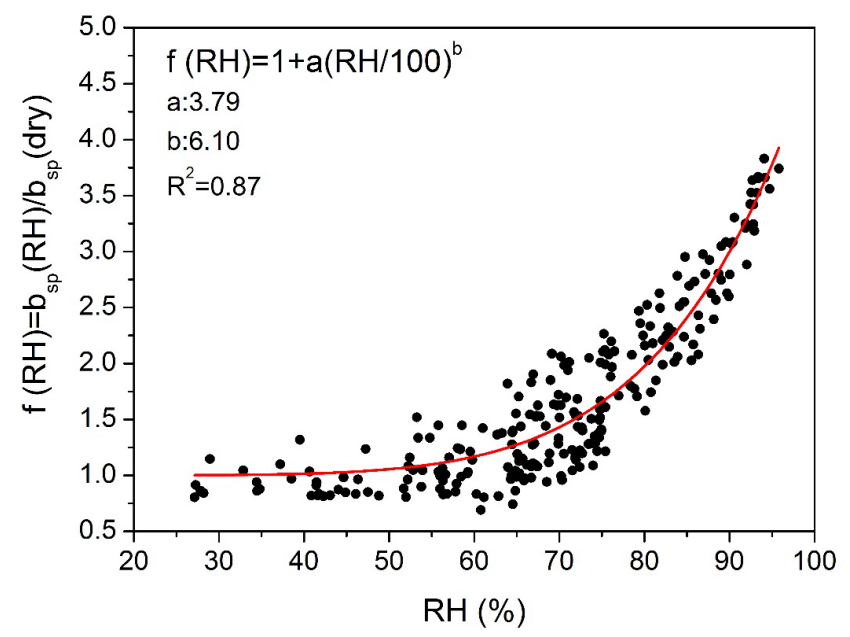

Figure 14. Hygroscopic growth for aerosol scattering $f(\mathrm{RH})$ as a function of RH with curve fitting. Scattered dots are the measured $f(\mathrm{RH})$ values, and the line is the empirical fitting curve.

actant. Hence, when RH was $>40 \%$, the high RH became a major factor accelerating the production of $\mathrm{SO}_{4}^{2-}$. The conversion is an endothermic reaction, which indicates that high temperature can promote the conversion. $\mathrm{RH}$ and temperature have an inverse correlation. When the RH was lower than $40 \%$, water was not adequate to accelerate the conversion. As a result, the temperature became the most important factor in the reaction. Therefore, when the RH was lower than $40 \%$, SOR decreased with decreasing temperature but not with increasing $\mathrm{RH}$. The formation of $\mathrm{NO}_{3}^{-}$was more complex than that of $\mathrm{SO}_{4}^{2-}$, so the correlation of NOR and $\mathrm{RH}$ was much weaker than that of SOR and RH. However, a clear positive correlation was still observed. No minimum value was found for NOR, and high RH can promote NOR.

The measured $f(\mathrm{RH})$ values at ambient $\mathrm{RH}$ during the observed period were depicted in Fig. 14. The curve was similar to those of other studies, indicating an increasing tendency of $f(\mathrm{RH})$ with increasing $\mathrm{RH}$. Usually, the exponential relationship between $f(\mathrm{RH})$ and $\mathrm{RH}$ can be fitted by an empirical function: $f(\mathrm{RH})=1+a(\mathrm{RH} / 100)^{b}$. In this study, the curve-fitting parameters $a$ and $b$ were 3.79 and 6.10 , respec-

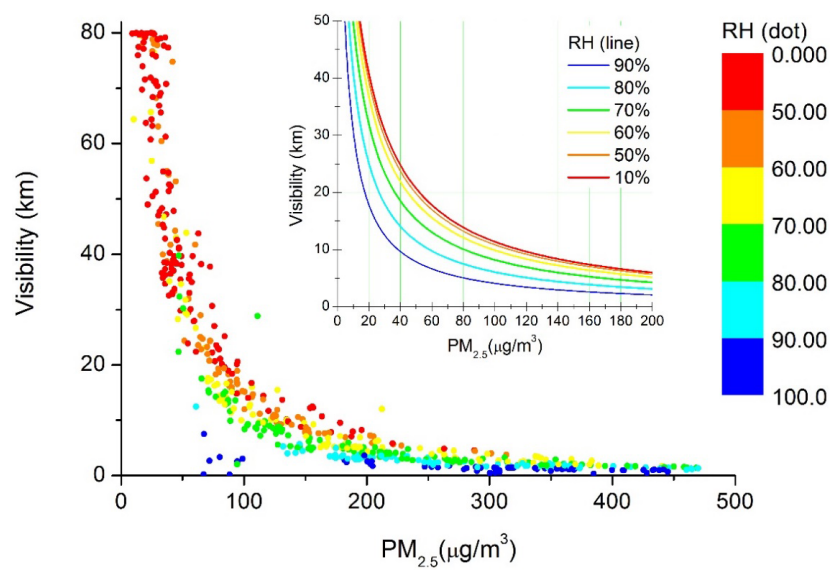

Figure 15. Variation of visibility at different $\mathrm{RH}$ values and different concentrations of $\mathrm{PM}_{2.5}$, observed (dots) and simulated (lines).

tively. $f(\mathrm{RH})$ values at an $\mathrm{RH}$ of $80 \%$, which had an average value of 1.97 in this study, were extracted for comparison with other studies. When the RH was $80 \%$, the aerosol particulate scattering coefficient was nearly 2 times of that in dry conditions, which was relatively large compared with other studies (Liu et al., 2013a). Consequently, the RH contributed much more to aerosol extinctions in October 2014, leading to more severe hazes.

Visibility dependences on the mass concentration of $\mathrm{PM}_{2.5}$ at different RH intervals were shown in Fig. 15. Overall, the visibility decreased rapidly with increasing $\mathrm{PM}_{2.5}$ concentration. In addition, with increasing RH, the visibility decreased faster. For example, when the RH was less than $30 \%$, and the mass concentration of $\mathrm{PM}_{2.5}$ was lower than $85 \mu \mathrm{g} \mathrm{m}{ }^{-3}$, all of the visibilities were over $10 \mathrm{~km}$. However, when the RH was greater than $90 \%$, no visibility was more than $10 \mathrm{~km}$ in this observation. To quantify the relationship between visibility, the $\mathrm{PM}_{2.5}$ concentration and RH, Eq. (9) was used:

$$
\begin{aligned}
b_{\text {ext }}(\mathrm{RH})= & b_{\text {sp }}(\mathrm{RH})+b_{\text {ap }}+b_{\text {sg }}+b_{\text {ag }}=Q_{\mathrm{SP}} \times \mathrm{PM}_{2.5} \\
& \times\left(1+a \times\left(\frac{\mathrm{RH}}{100}\right)^{b}\right)+Q_{\text {ap }} \times \mathrm{PM}_{2.5}+34,
\end{aligned}
$$

where $Q_{\mathrm{sp}}$ and $Q_{\mathrm{ap}}$ were the mass scattering and absorbing efficiency, which were the ratios of $b_{\mathrm{sp}}$ and $b_{\mathrm{ap}}$ to $\mathrm{PM}_{2.5}$, respectively. The average values of $Q_{\mathrm{sp}}$ and $Q_{\mathrm{ap}}$ in this study were 3.10 and $0.42 \mathrm{~m}^{2} \mathrm{~g}^{-1}$. Curves of the dependence of visibility on the $\mathrm{PM}_{2.5}$ concentration at different $\mathrm{RH}$ intervals were shown in Fig. 15. The calculated curves showed the same trend as the dotted figure: the higher the RH was, the faster the visibility decreased as the concentration of $\mathrm{PM}_{2.5}$ increased. When the concentration of $\mathrm{PM}_{2.5}$ reached $75 \mu \mathrm{g} \mathrm{m}^{-3}$ (the national secondary standard of $\mathrm{PM}_{2.5}$ ), the visibility surpassed $10 \mathrm{~km}$ only when the RH was lower than $60 \%$. To control haze, keeping $\mathrm{PM}_{2.5}$ under the national second standard alone was sufficient. 
In previous studies, a temperature decrease was often reported (Liu et al., 2013b). It not only deprived the dynamics of the PBL development, but also resulted in less heat turbulence, which was unfavorable for pollutant dispersion. Moreover, negative aerosol radiation forcing (ARF) was always recorded, indicating the feedback mechanism between radiation and aerosol loading (Quan et al., 2014). However, in this study, even though the solar radiation was reduced during the haze episodes, the temperature was steady or even increasing over a longer temporal range (several days). Water vapor, a greenhouse gas, had a vital effect on the atmospheric thermal balance. The short-wave radiation from the sun was not absorbed by water vapor, but the long-wave radiation from the Earth can be largely absorbed by it. As a result, even less solar radiation reached the Earth's surface, and the radiation from the Earth supplied increasing heat to the atmosphere with increasing $\mathrm{RH}$. Increasing temperature accelerated the chemical reaction rate of aerosols and aggravated the haze. This situation could also be found in the haze in January 2013, but little research has focused on the temperature variation. Figure 16 depicted how RH influenced the haze formation. Water vapor in the atmosphere played a vital role in the formation of haze, which could not only accelerate the chemical transformation of secondary pollutants but also lead to hygroscopic growth of aerosols. Furthermore, as an important greenhouse gas, it absorbed surface radiation, altering the thermal balance of the atmosphere, which finally affected haze formation. RH in autumn was much higher than winter (Dong et al., 2013). It highly increased the rate of secondary reaction and hygroscopic growth. Thus, when only considering $\mathrm{RH}$, with the same level of emission haze in autumn would be more severe. However, in reality a larger quantity of emissions and increasing $\mathrm{RH}$ in last decade in winter (Cheng et al., 2015) resulted in heavier haze in the winter season.

\section{Conclusions}

Most studies concerning haze events in the NCP were performed in the winter and summer, concluding that intense secondary formation, huge regional transport of pollutants, stationary meteorological conditions and large local emissions were most considered to be major factors leading to severe hazes. Formation of hazes in autumn, during which biomass burning and movement of wind based on large scale topography was important, was less reported. Moreover, overall analysis on the role of humidity was always missing in case studies, while humidity would impact the formation process from many aspects.

Comprehensive measurements were conducted during the haze episode from 5 October to 2 November 2014. To clarify the formation mechanism of haze in Beijing, the physical and chemical characteristics of aerosol and the relevant meteorology parameters were analyzed. Particularly, comprehensive

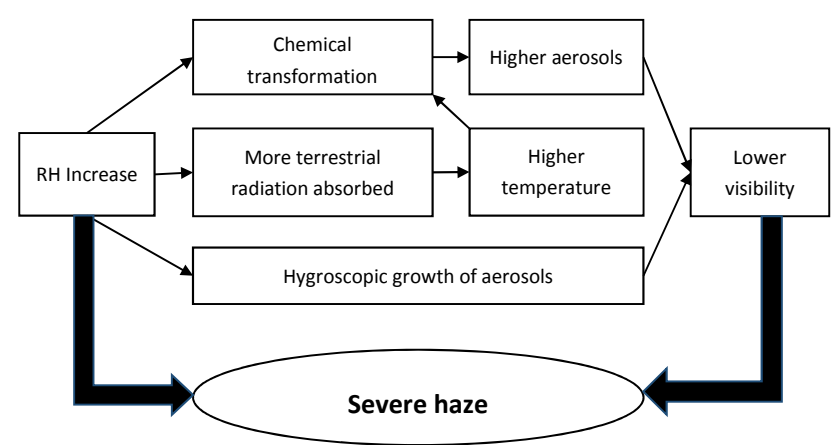

Figure 16. The mechanism of how RH influenced haze formation.

influence of humidity on haze formation was presented. At last, three major ways how humidity worked on formation mechanism of hazes were put forward.

The major conclusions were as follows:

1. Four distinct haze episodes occurred in October 2014 in Beijing, China. The increasing rate of the concentration of $\mathrm{PM}_{2.5}$, which was seldom mentioned before, was used to analyze the formation progress of hazes. The highest concentration of $\mathrm{PM}_{2.5}$ was $469 \mu \mathrm{g} \mathrm{m}^{-3}$ in Beijing. The highest increasing rate of the concentration of $\mathrm{PM}_{2.5}$, was $4.44 \mu \mathrm{g} \mathrm{m}^{-3} \mathrm{~h}^{-1}$. The haze originated from the North China Plain (NCP), developing in the southwest and northeast directions.

2. The concentration of $\mathrm{SO}_{4}^{2-}$ was lower than that of $\mathrm{NO}_{3}^{-}$. However, The increasing rate of the SOR and NOR was introduced into this research, showing the oxidation rate of $\mathrm{SO}_{2}$ to $\mathrm{SO}_{4}^{2-}$ was faster than that of $\mathrm{NO}_{2}$ to $\mathrm{NO}_{3}^{-}$. Sharp increases in the SNA fraction in $\mathrm{PM}_{1}$ in the haze episode indicated that new formation of SNA contributed most to the formation of haze.

3. In total, 54, 26 and 57 fire points were found in Hebei, Henan and Shandong provinces, respectively. The air mass during the first haze episodes mainly came from the south and southeast, originating from these provinces. The sudden increase in the concentration of organic matter, $\mathrm{Cl}^{-}$and $\mathrm{BC}$ before each haze period indicated the importance of biomass burning and transport in the beginning of haze in October 2014, after which the increase of new SNA were predominant in haze formation.

4. The NCP was dominated by a weak high-pressure system during haze episodes. Beijing city slowed the wind speed and disturbed the wind direction. Overall, the winds blew from the northwest, northeast, and southwest. The $\mathrm{PM}_{2.5}$ concentrations were relatively high within the wind speed boundary: $1 \mathrm{~m} \mathrm{~s}^{-1}$ for wind from the northwest, $1.5 \mathrm{~m} \mathrm{~s}^{-1}$ for wind from the northeast and $3 \mathrm{~m} \mathrm{~s}^{-1}$ for wind from the southwest. 
5. A distinct decrease in the PBL height was observed during the four haze periods, compressing the local pollutants closer to the surface.

6. The four haze episodes in October 2014 were characterized by higher RH. High RH influenced the haze formation in three ways: accelerating the chemical transformation of secondary pollutants, leading to hygroscopic growth of aerosols and altering the thermal balance of the atmosphere.

\section{The Supplement related to this article is available online at doi:10.5194/acp-15-8165-2015-supplement.}

Acknowledgements. This work was supported by the National Natural Science Foundation of China (No. 41175018 and No. 41475113) and by special fund of State Key Joint Laboratory of Environment Simulation and Pollution Control (No. 14L02ESPC).

Edited by: V.-M. Kerminen

\section{References}

Araujo, J. A., Barajas, B., Kleinman, M., Wang, X., Bennett, B. J., Gong, K. W., Navab, M., Harkema, J., Sioutas, C., Lusis, A. J., and Nel, A. E.: Ambient particulate pollutants in the ultrafine range promote early atherosclerosis and systemic oxidative stress, Circ. Res., 102, 589-596, 2008.

Cahill, T. A.: Climate forcing by anthropogenic aerosols: the role for PIXE, Nucl. Instrum. Methods Phys. Res. Sect. B: Beam Interact. Mater., B 109, 402-406, 1996.

Cheng, Y., He, K. B., Du, Z. Y., Zheng, M., Duan, F. K., and Ma, Y. L.: Humidity plays an important role in the PM2.5 pollution in Beijing, Environ. Pollut., 197, 68-95, 2015.

Dong, X. L., Liu, D. M., Gao, S. P.: Seasonal variations of atmospheric heterocyclic aromatic amines in Beijing, China, Atmos. Res., 120-121, 287-297, 2013.

Fu, Q., Zhuang, G., Wang, J., Xu, C., Huang, K., Li, J., Hou, B., Lu, T., and Streets, D. G.: Mechanism of formation of the heaviest pollution episode ever recorded in the Yangtze River Delta, China, Atmos. Environ., 42, 2023-2036, 2008.

Garland, R. M., Yang, H., Schmid, O., Rose, D., Nowak, A., Achtert, P., Wiedensohler, A., Takegawa, N., Kita, K., Miyazaki, Y., Kondo, Y., Hu, M., Shao, M., Zeng, L. M., Zhang, Y. H., Andreae, M. O., and Pöschl, U.: Aerosol optical properties in a rural environment near the mega-city Guangzhou, China: implications for regional air pollution, radiative forcing and remote sensing, Atmos. Chem. Phys., 8, 5161-5186, doi:10.5194/acp-85161-2008, 2008.

Guo, S., Hu, M., Zamora, M. L., Peng, J., Shang, D., Zheng, J., Du Z, Wu, Z., Shao, M., Zeng, L., Molina, M. J., and Zhang, R.: Elucidating severe urban haze formation in China, P. Natl. Acad. Sci. USA, 111, 17373-17378, 2014.
Han, T., Liu, X., Zhang, Y., Qu, Y., Gu, J., Ma, Q., Lu, K., Tian, H., Chen, J., Zeng, L., Hu, M., and Zhu, T.: Characteristics of Aerosol Optical Properties and Their Chemical Apportionments during CAREBeijing 2006, Aerosol Air Qual. Res., 14, 1431$1442,2014$.

He, H., Wang, Y., Ma, Q., Ma, J., Chu, B., Ji, D., Tang, G., Liu, C., Zhang, H., and Hao, J.: Mineral dust and NOx promote the conversion of $\mathrm{SO}_{2}$ to sulfate in heavy pollution days, Sci. Rep., 4, 4172, doi:10.1038/srep04172, 2014.

Hodkinson, J. R.: Calculation of colour and visibility in urban atmospheres polluted by gaseous $\mathrm{NO}_{2}$, Air Water Pollut., 10, $137-$ 144, 1966.

Hu, J. L., Wang, Y. G., Ying, Q., and Zhang, H. L.: Spatial and temporal variability of PM2.5 and PM10 over the North China plain and the Yangtze River delta, China, Atmos. Environ., 95, 598-609, 2014.

Huang, K., Zhuang, G., Wang, Q., Fu, J. S., Lin, Y., Liu, T., Han, L., and Deng, C.: Extreme haze pollution in Beijing during January 2013: chemical characteristics, formation mechanism and role of fog processing, Atmos. Chem. Phys. Discuss., 14, 7517-7556, doi:10.5194/acpd-14-7517-2014, 2014.

Jacobson, M. Z.: Strong radiative heating due to the mixing state of black carbon in atmospheric aerosols, Nature, 409, 695-697, 2001.

Ji, D., Li, L., Wang, Y., Zhang, J., Cheng, M., Sun, Y., Liu, Z., Wang, L., Tang, G., Hu, B., Chao, N., Wen, T., and Miao, H.: The heaviest particulate air-pollution episodes occurred in northern China in January, 2013: Insights gained from observation, Atmos. Environ., 92, 546-556, 2014.

Jung, J., Lee, H., Kim, Y. J., Liu, X., Zhang, Y., Gu, J., and Fan, S.: Aerosol chemistry and the effect of aerosol water content on visibility impairment and radiative forcing in Guangzhou during the 2006 Pearl River Delta campaign, J. Environ. Manage., 90, 3231-3244, 2009

Koschmieder, H.: Theorie der horizontalen Sichtweite, Beiträge zur Physik der freien Atmosphäre, 33-53, 1924.

Li, W. J., Shao, L. Y., and Buseck, P. R.: Haze types in Beijing and the influence of agricultural biomass burning, Atmos. Chem. Phys., 10, 8119-8130, doi:10.5194/acp-10-8119-2010, 2010.

Liao, X. N., Zhang, X. L., Wang, Y. C., Liu, W. D., Du, J., and Zhao, L. H.: Comparative analysis on meteorological condition for persistent haze cases in summer and winter in Beijing (With abstract in English), Environ. Sci., 35, 2031-2044, 2014.

Liu, X. G., Cheng, Y. F., Zhang, Y. H., Jung, J. S., Sugimoto, N., Chang, S. Y., Kim, Y. J., Fan, S. J., and Zeng, L. M.: Influences of relative humidity and particle chemical composition on aerosol scattering properties during the 2006 PRD campaign, Atmos. Environ., 42, 1525-1536, 2008.

Liu, X. G., Zhang, Y. H., Gu, J. W., Li, Y. P., Cheng, Y. F., Qu, Y., Han, T. T., Wang, J. L., Tian, H. Z., Chen, J., and Zhang, Y. H.: Increase of aerosol scattering by hygroscopic growth: Observation, modeling, and implications on visibility, Atmos. Res., 132-133, 91-101, 2013a.

Liu, X. G., Li, J., Qu, Y., Han, T., Hou, L., Gu, J., Chen, C., Yang, Y., Liu, X., Yang, T., Zhang, Y., Tian, H., and Hu, M.: Formation and evolution mechanism of regional haze: a case study in the megacity Beijing, China, Atmos. Chem. Phys., 13, 4501-4514, doi:10.5194/acp-13-4501-2013, 2013 b. 
Ma, N., Zhao, C. S., Nowak, A., Müller, T., Pfeifer, S., Cheng, Y. F., Deng, Z.Z., Liu, P. F., Xu, W. Y., Ran, L., Yan, P., Göbel, T., Hallbauer, E., Mildenberger, K., Henning, S., Yu, J., Chen, L. L., Zhou, X. J., Stratmann, F., and Wiedensohler, A.: Aerosol optical properties in the North China Plain during HaChi campaign: an in-situ optical closure study, Atmos. Chem. Phys., 11, 59595973, doi:10.5194/acp-11-5959-2011, 2011.

Miao, S., Chen, F., LeMone, M. A., Tewari, M., Li, Q., and Wang, Y.: An Observational and Modeling Study of Characteristics of Urban Heat Island and Boundary Layer Structures in Beijing, J. Appl. Meterol. Clim., 48, 484-501, 2009.

Miller, K. A., Siscovick, D. S., Sheppard, L., Shepherd, K., Sullivan, J. H., Anderson, G. L., and Kaufman, J. D.: Long-term exposure to air pollution and incidence of cardiovascular events in women, N. Engl. J. Med., 356, 447-458, 2007.

Quan, J., Tie, X., Zhang, Q., Liu, Q., Li, X., Gao, Y., and Zhao, D.: Characteristics of heavy aerosol pollution during the 2012-2013 winter in Beijing, China, Atmos. Environ., 88, 83-89, 2014.

Pal, S., Lee, T. R., Phelps, S., De Wekker, S. F. J.: Impact of atmospheric boundary layer depth variability and wind reversal on the diurnal variability of aerosol concentration at a valley site, Sci. Total Environ., 496, 424-434, 2014.

Pal, S., Lopez, M., Schmidt, M., Ramonet, M., Gibert, F., Xueref Remy, I., and Ciais, P.: Investigation of the atmospheric boundary layer depth variability and its impact on the $222 \mathrm{Rn}$ concentration at a rural site in France, J. Geophys. Res., 120, 623-643, 2015.

Sun, Y., Zhuang, G., Tang, A. A., Wang, Y., and An, Z.: Chemical characteristics of PM2.5 and PM10 in haze-fog episodes in Beijing, Environ. Sci. Technol., 40, 3148-3155, 2006.

Sun, Y., Jiang, Q., Wang, Z., Fu, P., Li, J., Yang, T., and Yin, Y.: Investigation of the sources and evolution processes of severe haze pollution in Beijing in January 2013, J. Geophys. Res.-Atmos., 119, 4380-4398, 2014.

Sun, Y. L., Wang, Z. F., Fu, P. Q., Yang, T., Jiang, Q., Dong, H. B., Li, J., and Jia, J. J.: Aerosol composition, sources and processes during wintertime in Beijing, China, Atmos. Chem. Phys., 13, 4577-4592, doi:10.5194/acp-13-4577-2013, 2013.

Tao, M., Chen, L., Wang, Z., Ma, P., Tao, J., and Jia, S.: A study of urban pollution and haze clouds over northern China during the dusty season based on satellite and surface observations, Atmos. Environ., 82, 183-192, 2014a.

Tao, M., Chen, L., Xiong, X., Zhang, M., Ma, P., Tao, J., and Wang, Z.: Formation process of the widespread extreme haze pollution over northern China in January 2013: Implications for regional air quality and climate, Atmos. Environ., 98, 417-425, 2014 b.
Wang, H., Xu, J., Zhang, M., Yang, Y., Shen, X., Wang, Y., Chen, D., and Guo, J.: A study of the meteorological causes of a prolonged and severe haze episode in January 2013 over centraleastern China, Atmos. Environ., 98, 146-157, 2014.

Wang, W., Maenhaut, W., Yang, W., Liu, X., Bai, Z., Zhang, T., Claeys, M., Cachier, H., Dong, S., and Wang, Y.: One-year aerosol characterization study for PM2.5 and PM10 in Beijing, Atmos. Pollut. Res., 5, 554, 2014.

Watson, J. G.: Visibility: Science and regulation, J. Air Waste Manage., 52, 628-713, 2002.

Wu, D., Bi, X., Deng, X., Li, F., Tan, H., Liao, G., and Huang, J.: Effect of Atmospheric Haze on the Deterioration of Visibility over the Pearl River Delta, Acta Meteorol. Sin., 21, 215, 2007.

Xue, J., Griffith, S. M., Yu, X., Lau, A. K. H., and Yu, J. Z.: Effect of nitrate and sulfate relative abundance in PM2.5 on liquid water content explored through half-hourly observations of inorganic soluble aerosols at a polluted receptor site, Atmos. Environ., 99, 24-31, 2014

Yang, Y., Liu, X., Qu, Y., Wang, J., An, J., Zhang, Y., and Zhang, F.: Formation mechanism of continuous extreme haze episodes in the megacity Beijing, China, in January 2013, Atmos. Res., 155, 192-203, 2015.

Zhang, J. K., Sun, Y., Liu, Z. R., Ji, D. S., Hu, B., Liu, Q., and Wang, Y. S.: Characterization of submicron aerosols during a month of serious pollution in Beijing, 2013, Atmos. Chem. Phys., 14, 2887-2903, doi:10.5194/acp-14-2887-2014, 2014.

Zhang, Z. Y., Zhang, X. L., Gong, D. Y., Quan, W. J., Zhao, X. J., Ma, Z. Q., and Kim, S. J.: Evolution of surface $\mathrm{O}_{3}$ and PM2.5 concentrations and their relationships with meteorological conditions over the last decade in Beijing, Atmos. Environ., 108, 67-75, 2015.

Zhao, P., Zhao, X., Zhang, X., and Xu, X.: Long-term visibility trends and characteristics in the region of Beijing, Tianjin, and Hebei, China, Atmos. Res., 101, 711-718, 2011.

Zhao, X. J., Zhao, P. S., Xu, J., Meng, W., Pu, W. W., Dong, F., He, D., and Shi, Q. F.: Analysis of a winter regional haze event and its formation mechanism in the North China Plain, Atmos. Chem. Phys., 13, 5685-5696, doi:10.5194/acp-13-5685-2013, 2013. 